\title{
Fanning the Flames (After Lighting the Spark): Multi-Trade COMET Programs
}

\author{
Jeff Grabelsky, Adam Pagnucco and Steve Rockafellow
}

The COMET (Construction Organizing Membership Education Training) is an educational program utilized by building trades unions to generate rank and file support for organizing new members. Since 1996, the Building and Construction Trades Department of the AFL-CIO has been sponsoring COMET training in multi-trade settings for its fifteen affiliates. Between 1997 and 1998, the Department undertook a systematic evaluation of its multi-trade COMET programs to determine their impact on attitudes toward organizing as well as on the nature and extent of organizing activities. This article summarizes the lessons the Department learned. Among other conclusions, the evaluation reaffirmed that COMET training is an effective way to build internal support for external organizing and that local unions using the COMET appear to be more deeply engaged in organizing than those not using this innovative labor education program.

\section{Introduction}

The COMET (Construction Organizing Membership Education Training) - an educational program designed to generate rank and file support for organizing - has impacted construction markets across the United States and Canada. ${ }^{1}$ (Grabelsky 4-21) In virtually every city, construction workers participate in COMET training, adorn their hard hats with COMET stickers, wear COMET pins, sport COMET T-shirts, decorate job sites with COMET posters and distribute COMET leaflets to co-workers. And, in many of these cities, building trades unions endeavor to unionize unrepresented construction workers, organize nonunion contractors and reclaim markets lost to the open shop.

Since the COMET was first launched by the IBEW in 1988, the AFL-CIO's Building and Construction Trades Department (referred to as "BCTD" or "Department") and each of its international affiliates have embraced this innovative program. Over 100,000 rank and file members, as well as an undetermined number of unrepresented workers, have participated in the three-hour COMET class. Specially-trained COMET instructors help members understand why union density in the construction industry has declined dramatically, how that decline affects unions and workers, and what unions and their members can do about it. The Department has been sponsoring COMET Train-the-Trainer Courses since 1994, usually in conjunction with state and local building trades councils, sometimes at the George Meany

\footnotetext{
${ }^{1}$ For a discussion of the causes and consequences of union decline in the construction industry, the emergence of an organizing movement, and the development, design and delivery of the COMET program, see Jeff Grabelsky, "Lighting the Spark: COMET Program Mobilizes the Ranks for Construction Organizing," Labor Studies Journal. Spring, 1995.
} 
Center for Labor Studies. In1997, the Department initiated an evaluation process to determine the value and impact of its COMET programs. This article summarizes what the Department learned.

\section{Why the Building and Construction Trades Department Evaluated its COMET Training Programs}

In recent years the Department has played an increasingly prominent role in promoting an organizing agenda among building trades unions and councils across the country. The Department has worked closely with the George Meany Center in training construction organizers from all trades, collaborated with regional building trades councils in conducting COMET Train-the-Trainer Courses, co-sponsored the development and delivery of the COMET II program, assisted its affiliates in a variety of educational seminars, and devoted considerable attention to organizing at its annual national conferences. In 1996, the Department helped initiate the Building Trades Organizing Project, or BTOP, a multi-trade, market-wide organizing campaign in Las Vegas.

All of these efforts, as well as the activities of affiliates at the national and local levels, have contributed to a deepening commitment to organizing among building trades unionists. They have also heightened the demand for additional Department programs to support and sustain an emerging construction organizing movement. For example, COMET II, which focuses on "Worksite Organizing with COMET Activists," was developed to provide training for rank and file volunteers who emerged from COMET I classes understanding why unions need to organize and wishing to learn how to do it. The Department recognized that it did not have sufficient staff and resources to meet that demand and prepared to make strategic decisions about where and how it should direct its efforts to maximize their impact. The first step, it reasoned, was to systematically evaluate the training programs it had already helped deliver.

\section{How the Department Evaluated its COMET Train-the-Trainer Courses}

The Department obtained attendance records on 352 attendees at 15 COMET I and COMET II Train-the-Trainer courses taught in multi-trade settings between 1994 and 1997. Of these 352, 153 took COMET 1,164 took COMET II, and 35 took both. Of the 15 courses, ten were sponsored by one of six building trades councils. Several others were conducted at the George Meany Center. The Department's evaluation process included input from both participants and council leaders who sponsored the courses.

Participants were surveyed in three stages, described below:

1. Short Surveys:

One page surveys (front and back), separately drafted for COMET I and COMET II, were mailed to the 352 attendees. If council leaders who sponsored the Train-the-Trainer Courses participated, they were included in the short survey process. Each survey asked six questions about the participants themselves (their local, title, council, city and state) and seven questions about their experiences in teaching the COMET classes to members. Questions related to the COMET delivery included how many classes they taught, how many members they trained, and 
whether they had problems teaching. The COMET I survey contained six questions on organizing activity undertaken by the local; the COMET II survey contained ten such questions. Participants were given the option of completing the surveys anonymously or volunteering to be further surveyed. Ninety-three respondents completed the COMET I short survey, 75 completed the COMET II short survey, and 57 indicated they wanted to be surveyed further.

2. Long Surveys:

The 57 people who were willing to be surveyed further were sent 17-page, 11-part comprehensive surveys, again separately drafted for COMET I and COMET II. The questions concerned participant information, local union information, evaluation of the COMET Train-theTrainer Course, experience delivering the COMET class itself, attitudes of members towards COMET, and organizing activity undertaken by local unions as well as their building trades council. Some questions were directed only to council leaders. Twenty-four responded to the COMET I survey; 18 responded to the COMET II survey. Most of the responses to the COMET II survey were incomplete.

3. Telephone Interviews

The Department had phone numbers for 32 of the 57 people who wanted to be surveyed further. Of these, 17 participants were contacted and interviewed through telephone calls. Questions asked in the calls complemented those in the long surveys, and often corroborated data from the written surveys. Participants were also encouraged to complete the long surveys they had received.

In addition to seeking input from participants, the Department reached out to officials of the six councils that had sponsored COMET Train-the-Trainer courses. These individuals were contacted by telephone, along with one former council leader now employed by the BCTD. Of these seven, five were available for telephone interviews. Council leaders were asked why they sponsored train-the-trainer courses, how they evaluated their impact, and what organizing activities had occurred as a result.

Moreover, as indicated above, council leaders who participated in COMET I and/or II Train-the-Trainer Courses were asked to complete appropriate written surveys. Several did.

\section{Limitations of the Department's Evaluation Process}

Although the Department's evaluation of the COMET program was more rigorous than most previous efforts, it suffered from a number of limitations that temper the strength of its conclusions.

First, the sample size was relatively small. Given a universe of several thousand COMET trainers, most of whom participated in affiliate-specific train-the-trainer courses, the Department's evaluation sought the input of only 350 instructors from multi-trade programs. Of those, over 150 responded, a relatively high rate. The multi-stage nature of the evaluation process, with short surveys, followed by long surveys, and finally phone interviews, was designed to mitigate against the limitations of the small sample size.

Second, respondents probably represented a selective group of instructors who have had a positive experience with COMET and whose responses are likely to be skewed in favor of the COMET. The Department conjectured that those individuals who felt critical or indifferent 
toward the COMET were more likely to abstain from the survey process. To the extent that assumption is true, the Department's evaluation may be biased.

Third, the evaluation was based almost entirely on the perceptions of the respondents. The Department made no effort to independently corroborate the judgments offered by survey participants.

Fourth, the evaluation was largely retrospective in nature, did not benefit from an examination of any control groups untouched by the COMET, and involved no pre-COMET baseline surveys to demonstrate a clear link between COMET training and changes in attitudes toward organizing or the level and effectiveness of organizing.

Nevertheless, the evaluation process enabled the Department to learn a great deal about its COMET Train-the-Trainer Courses.

\section{What the Department Learned}

Department leaders and staff, like many others in the building trades, had long regarded the COMET as an enormously effective tool to generate membership support for organizing unrepresented workers and to help transform locals into organizing unions. That view, previously supported primarily by personal experience and anecdotal evidence, was strongly reaffirmed by the Department's formal evaluation.

Building trades leaders interviewed by the Department suggested that the COMET had inspired a growing optimism within their councils. "We have a renewed sense of the future," reported one leader. "COMET has shown us a light at the end of the tunnel," declared another, "It has sparked something in all of us... We were in a rut... [and] didn't see the need to change paths. COMET has woken us up."

Leaders claimed that COMET helped promote cohesion and advance an organizing agenda within their councils. "We used to sit in a room and argue for our particular interests," one council leader explained. "Now we have found a common interest: organizing. Organizing overshadows the other problems that had been typical..." Another leader believed COMET helped strengthen his council by provoking "drastic changes." "There is a new spirit of optimism and increased level of harmony among council affiliates," he observed.

The sense of hope and determination leaders witnessed in their councils seemed to reflect a change within the locals' membership. One leader spoke of a "new spirit of solidarity among the rank and file... Members are again proud to be union."

Beyond these anecdotes and testimonials, the Department discovered that, by virtually every statistical measure, the COMET is, in fact, a powerful program that promotes construction organizing and its impact deepens the more widely it is used.

\section{Results of the Comet I Short Survey}

Ninety-three participants representing twelve international unions responded to the COMET I short survey. Half of the respondents were local organizers or business agents and representatives; only $2 \%$ were business managers. A fraction of the respondents were from the 
South; the overwhelming majority were nearly evenly distributed between the Northeast, West and Midwest. Respondents reported teaching 1,191 COMET I classes on behalf of local unions and 42 classes sponsored by building trades councils. They presented the COMET I to a combined 17,731 members. On average respondents taught just over 13 classes to 199 people in groups of approximately 15 members. Fifteen percent reported teaching no COMET I classes at all.

Having been prepared to deliver the COMET I class by participating in a four-day intensive train-the-trainer course, $47 \%$ of the respondents indicated that they encountered no problems in teaching the COMET to rank and file members. One quarter identified attendance as a problem.

Ninety-eight percent of the respondents said that the COMET I Train-the-Trainer Course had a positive impact on their own attitudes toward organizing and $83 \%$ believed that when the COMET I class was delivered to their local's rank and file, it had a positive impact on the members.

The Department sought to determine how the COMET influenced organizing activities in sponsoring locals. The short survey identified six measures of organizing and asked respondents to report if their local engaged in the noted activity before and after COMET delivery. The results are summarized below: sponsoring locals. The short survey identified six measures of organizing and asked respondents to report if their local engaged in the noted activity before and after COMET delivery. The results are summarized below:

Organizing Activity

Organizing is regular item on local union's

meeting agenda

Local union is salting ${ }^{2}$

Members reach out to unrepresented workers on mixed jobsites

Local union has altered policies which impede organizing $^{3}$

Local union has brought in new members through organizing

Local union employs full-time construction organizer

$\%$ Reporting that this took place:

Before COMET I After COMET I

$27 \%$

14

14

18

43

36
$72 \%$

71

66

62

79

53

\footnotetext{
${ }^{2}$ Salting is a tactic in which union activists go to work for nonunion employers for the purpose of organizing.

${ }^{3}$ Building trades locals often adhere to internal union policies and procedures mat are obstacles to organizing new members. These include: restrictive membership policies, referral procedures that discriminate against newly organized workers, apprenticeship standards that preclude

"slotting" lesser skilled, newly organized members into programs for upgrading, high initiation fees, etc.
} 


\section{Summary of COMET I Frequency Distribution and Cross-Tabulation}

Department analysts also ran frequency distributions and cross-tabulations on the COMET I short survey data. They discovered that a distinct minority of respondents taught the majority of the COMET I classes. While $14 \%$ reported teaching no classes, another $14 \%$, or thirteen respondents, taught $51 \%$ of all the COMET I classes. In fact, about $30 \%$ of the respondents taught fully $80 \%$ of the classes.

Similarly, a minority of respondents taught the majority of the members. Fifteen percent taught no members, 35\% taught between one and 100 members, $35 \%$ taught between 100 and 300 members and $16 \%$ taught more than 300 members. Twelve respondents, or $13 \%$, taught $50 \%$ of the members. About $30 \%$ of the respondents taught $80 \%$ of the members.

According to instructors who completed the short survey, the more widely used the COMET I class, the more effective it was in changing members attitudes and generating organizing activity. Locals in which ten or more COMET I classes had been taught were much more likely to experience increases in salting, membership communication with unrepresented workers, and alteration of local policies that impede organizing than were locals that presented nine or fewer COMET I classes.

\section{Results of the COMET I Long Survey}

Of those respondents who expressed a desire and/or willingness to provide additional input, 24 completed the more comprehensive, 17-page survey. The overwhelming majority of these respondents had been in their current position for less than five years; more than half were 45 years old or younger; over $90 \%$ had been union members for more than ten years; $80 \%$ had entered their trade through the apprenticeship program; and almost all of them had taken at least one organizing class in addition to the COMET I Train-the-Trainer Course. The respondents represented a rather optimistic group: they all predicted growth in their construction markets over the next ten years; all but one anticipated that their local union's membership would rise over the next five years, and half of them expected their local membership to grow substantially.

Their reaction to the COMET I Train-the-Trainer Course was overwhelmingly positive on every measure asked. Before taking the course, only $13 \%$ would have strongly agreed that organizing unrepresented workers was the most effective way to re-establish the building trades as a vital force in the industry; after taking the course, $79 \%$ strongly agreed with this statement. Before taking the course, nearly half would have said that they were not sure or disagreed with the statement that raising standards of nonunion workers would improve union conditions; after taking the course, not one respondent disagreed. Before taking the course, only a fifth would have strongly agreed that an essential goal of the building trades should be that every construction worker have the opportunity to join a union; after taking the course, over $90 \%$ strongly agreed.

The Department was particularly interested in evaluating the impact of COMET on the attitudes of members and the dynamics of sponsoring locals. On average, respondents to the 
COMET I long survey taught just over twelve classes to about 225 members. Nearly half reported that $20 \%$ or less of their local's membership had attended a COMET I class. Almost three-quarters of the respondents complained that recruiting adequately-sized class of 20-25 members was very difficult. But when they delivered COMET, they judged it to be highly effective. For example, $80 \%$ of the respondents thought their members were skeptical or opposed to organizing before COMET I; after COMET I was taught, over $80 \%$ reported that their members now favored organizing. Only $8 \%$ of the respondents thought their members believed that raising nonunion standards would improve union conditions before COMET I; after COMET I was taught, 96\% said that their members now agreed with this. Respondents also reported that COMET promoted political harmony within their local unions. Before COMET I, one-fifth thought there was a high level of political harmony with the local union; after COMET I, one-half observed a high level of political harmony.

Beyond its impact on local union members, the Department sought to understand how COMET influenced the dynamics of building trades councils. Only $9 \%$ of the respondents thought that most local union representatives in their councils believed organizing would reestablish the local unions as a vital force in the industry before COMET I; after COMET I was taught to rank and file members, over $60 \%$ thought that most local representatives in their councils believed this. Respondents witnessed an expansion of organizing activities among council affiliates as a result of COMET training. For example, less than a fifth reported that local unions in their council were salting before COMET I; after COMET I, three-quarters said locals were salting. Only $13 \%$ believed that members of local affiliates were reaching out to unrepresented workers before COMET I; after COMET I, two-thirds said that members were doing so. Only one respondent said that most local unions in the council had altered policies that impeded organizing before COMET I; after COMET I, nearly half thought most locals had done so. Moreover, only $14 \%$ thought most local unions in their building trades council had brought in new members through organizing before COMET I; after COMET I, more than half reported that most affiliates had organized new members.

The Department was also pleased to learn that COMET training had enhanced its reputation among locals affiliated with building trades councils that sponsored COMET courses. For example, less than a quarter of the respondents thought that local unions in their councils highly regarded the Department before COMET I. That number nearly doubled after delivery of COMET classes.

\section{Results of COMET II Short Survey}

Seventy-five instructors representing eleven international unions responded to the COMET II short survey. Nearly half of the respondents were local organizers or business agents/representatives; only $3 \%$ were business managers. Like the COMET I short survey, a tiny fraction (only 1\%) were based in the South; the rest were fairly evenly distributed between the Northeast, West, and Midwest. They reported teaching 433 classes on behalf of local unions and just eight classes for their building trades council. Just over 5,000 members participated in the COMET II classes they delivered. On average, respondents taught about six classes to 77 people. Average class size was about 12 participants. 
Sixty percent reported teaching no classes or only one class. Having been prepared to deliver COMET II to rank and file activists by participating in a three-day COMET II Train-theTrainer Course, of those respondents who actually taught the class, 35\% reported no difficulties and $15 \%$ indicated that attendance was the main problem.

Ninety-six percent indicated that the COMET II Train-the-Trainer Course had a positive impact on them; and 79\% reported that when the COMET II class was delivered to rank and file members it had a positive impact on them. Respondents believed that their local unions were much more likely to engage in a range of organizing activities after delivery of the COMET II class. Because several respondents took both COMET I and COMET II Train-the-Trainer Courses, the Department could not determine how COMET I may have influenced the noted activities and found it difficult to interpret the results. Following are the percentages of respondents reporting that each activity listed took place before and after COMET II classes were taught to local union members:

\begin{tabular}{|c|c|c|}
\hline \multirow[b]{2}{*}{ Organizing Activity } & \multicolumn{2}{|c|}{ \%Reporting that this took place: } \\
\hline & Before COMET II & After COMET II \\
\hline Organizing is regular item on local union's meeting agenda & $49 \%$ & $82 \%$ \\
\hline Local union is salting & 30 & 87 \\
\hline Members reach out to unrepresented workers on mixed jobsites & 36 & 67 \\
\hline Local union has altered policies which impede organizing & 40 & 71 \\
\hline Local union has brought in new members through organizing & 57 & 82 \\
\hline Local union employs full-time construction organizer & 45 & 59 \\
\hline $\begin{array}{l}\text { Local union sends overt applicants to nonunion contractors } \\
\text { and files ULP charges }\end{array}$ & 20 & 73 \\
\hline NLRB has issued ULP complaints & 32 & 68 \\
\hline Local union has placed covert activists on nonunion jobsites & 31 & 78 \\
\hline $\begin{array}{l}\text { Local union has effectively used COMET II techniques, } \\
\text { particularly moving unrepresented workers }\end{array}$ & $16 \%$ & $68 \%$ \\
\hline
\end{tabular}

\section{Summary of COMET II Frequency Distributions and Cross-Tabulations}

As with the COMET I short surveys, Department analysts ran frequency distributions and cross-tabulations on data gathered from the COMET II short surveys. COMET II class presentations were even more concentrated among a distinct minority of trainers than were 
COMET I classes. Forty-one percent of the respondents reported teaching no classes and $17 \%$ reported teaching only one class. Sixteen percent of the respondents taught $81 \%$ of all the classes reported.

A tiny minority also taught most of the members. While forty percent of the respondents taught no members, only nine percent of the respondents reported teaching $72 \%$ of the members.

Some organizing activities undertaken by locals clearly increased with the number of COMET II classes taught. For example locals teaching ten or more COMET II classes were more likely to experience increases in salting, bringing in new members, filing ULP charges and getting complaints issued, and use of covert activists than were locals teaching nine or fewer COMET II classes.

\section{Summary of Interviews with Train-the-Trainer Course Participants}

Phone interviews were conducted with 17 participants from the COMET Train-theTrainer Courses who volunteered to offer additional feedback after completing the written surveys. The interviews explored four questions not extensively covered in the questionnaires: (1) Have respondents had any problems delivering the COMET classes? (2) Have they altered the class in any manner? (3) How have they used the COMET I and COMET II trainings in relation to each other and their local union's organizing activities? (4) What organizing activities have their local unions engaged in since the train-the-trainer course?

1. Have the respondents had any problems delivering the COMET?

The respondents overwhelmingly indicated that the COMET Train-the-Trainer Course thoroughly prepared them to conduct their own COMET classes. It was widely stated, however, that while a certain number of rank and file union members are easily attracted to the union hall to attend a COMET presentation, it was difficult to persuade the remaining members to attend. Although some local unions have successfully overcome this obstacle, it remains the biggest problem they face.

2. Have they altered the class in any manner?

The respondents generally believed that little or no changes are needed in the COMET program's content. Eighty percent of those holding classes said they have made little or no changes to the format, and follow the text as designed.

3. How have they used the COMET I and COMET II trainings in relation to each other and their local union's organizing activities?

The interviews indicated that many local unions have integrated COMET II topics into their COMET I classes. COMET II is being taught to many fewer rank and filers than COMET I. While COMET $I$ is designed to reach a majority of local members, the target audience for COMET II is a smaller group, i.e., those activists who emerge from COMET I understanding why the union needs to organize and wishing to help. Most respondents said that COMET I classes are held on a regular basis for each member, but that COMET II classes are only given to the activists who participate in the local union's organizing efforts. Some respondents said that COMET II classes were only given to such people on a "one-to-one" basis. 
4. What organizing activities have their local unions engaged in since the train-thetrainer course?

According to the interviewees, a majority of local unions have opened their doors to unorganized workers. This represents a dramatic shift away from the exclusionary membership philosophy characteristic of many local unions in the building trades. The respondents witnessed a widespread use of a narrow band of tactics: salting, the filing of ULP charges with the NLRB, and stripping. Some locals continue to use traditional "top down" tactics (e.g., efforts to persuade nonunion contractors to sign collective bargaining agreements without necessarily reaching out to their employees nor establishing the union's majority status) as part of their organizing program. But it appears that only a few local unions are successfully motivating unrepresented workers to organize their employers, and that some are using "top-down" organizing as part of the local union's organizing effort.

The interviews indicate that only a few local unions are not holding COMET classes and that these are the affiliates that rarely engage in bottom-up organizing. Interestingly, the small number of interviewees who revealed that their own local union was not using COMET gave no indication that they personally disagreed with its message or were skeptical of its effectiveness.

The majority of the COMET Train-the-Trainer Course participants interviewed expressed a strong desire to deepen their own level of knowledge about organizing, to elevate their local's organizing activities, and to increase their local union's market share. Most indicated that they had developed and implemented an organizing agenda within their local unions using the techniques outlined in COMET. These respondents spoke enthusiastically about COMET and expressed their optimism about the future.

\section{Summary of Interviews with Leaders of Sponsoring Councils}

Phone interviews were also conducted with five leaders of building and construction trades councils that sponsored COMET Train-the-Trainer Courses. The interviews reveal a consensus of opinion about the value of COMET training but raise the need for further discussion on the proper role of a council in delivering COMET and coordinating multi-trade organizing.

The responses offered by council leaders were overwhelmingly positive. Each acknowledged that, prior to COMET, the effectiveness of their council and local union had been declining. Each also observed a renewed spirit of optimism as a result of COMET and COMET inspired organizing. Council leaders agreed that jurisdictional bickering and other traditional sources of division among the trades have declined since COMET induced a new focus on organizing. Beyond improving the political climate within the councils, the leaders asserted that COMET has deepened their own understanding of construction organizing. They all believe COMET is an essential part of rebuilding construction unionism.

The interviews with council leaders also strengthened and supported the information received in the written surveys submitted by COMET Train-the-Trainer Course participants. Like the other participants, the council leaders felt that the train-the-trainer course thoroughly prepared them to teach COMET classes to members. They believed that little change was needed in the program's content. According to these leaders, COMET has taken construction 
organizing from non-existence a few years ago to an active state which includes salting, stripping, communicating with unrepresented workers, and the use NLRB procedures. These interviews reaffirm the view that construction organizing has not yet advanced to a level where large numbers of workers are being mobilized around concrete issues to organize their nonunion employers.

The interviewing process did not explicitly explore the appropriate role of a building and construction trades council in organizing. Multi-trade organizing appears to sporadically occur in the councils. All COMET sponsors expressed a preference for multi-trade organizing as the most effective way to re-unionize the industry. However, only a few leaders said their councils have actively attempted to play a leadership role in multi-trade organizing. Most leaders conceded that single-trade organizing still remains the norm within their councils. Those council leaders with some multi-trade organizing experience give strong testimony to its worth; those without such experience cited the council's financial limitations as the reason. Given the support and enthusiasm for multi-trade organizing conveyed by these leaders, there appears to be the basis for a national dialogue on the proper role of councils in coordinating organizing among multiple unions.

Finally, the interviews indicate that the BCTD has significantly bolstered its image as a leader and source of assistance to affiliated councils by sponsoring COMET Train-the-Trainer Courses. According to interviewees, COMET has clearly raised the level of respect that councilaffiliated local unions have for the Department, as well as increased the visibility of the BCTD to rank and file unionists.

According to the council leaders, the COMET program appears to be an overwhelming success. They claim that local unions that have adopted it have made impressive progress, while those that have not continue to languish.

\section{What the Department Concluded from its COMET Evaluation}

The Department drew a number of conclusions from the evaluation of its COMET programs. Some of these conclusions are summarized below:

1. Participants in the train-the-trainer courses as well as rank and file members who come to COMET classes appear to be profoundly changed by the experience. The overwhelming majority of both groups seem to emerge from COMET with a deeper understanding of the need to organize unrepresented workers and a stronger commitment to do so. Because it is exceedingly difficult to organize in the construction industry without membership support and participation, the Department will continue to promote COMET as an integral part of its organizing programs.

2. While the COMET-induced changes in attitudes toward organizing were clearly evident, an unmistakable connection between COMET training and actual organizing activity was more difficult to establish. Even though most survey respondents attested to that connection, the Department is concerned that COMET does more than promote a "culture of training." It will, therefore, encourage those who teach COMET to identify activists among rank and file class participants and quickly engage them in organizing activities. While recent trends indicate a rise 
in union density in the construction industry for two consecutive years, it is hard to measure how COMET-inspired organizing has contributed to that development. (Employment and Earnings Table 42)

3. Although the Department examined only train-the-trainer courses offered in multi-trade contexts, the results indicate that the overwhelming majority of COMET classes are being delivered on a single-trade basis. Despite the reported rise of a cooperative spirit among the trades after COMET, there is little evidence that attitude has translated into widespread multitrade training, let alone multi-trade organizing. The Department speculates that the paucity of such multi-trade activity may be indicative of a lack of clarity on the proper role of building trades councils in promoting, sponsoring, coordinating and sustaining multi-trade organizing, including COMET. In response, the Department has developed a set of guidelines called "Milestones to Organizing: A Systematic Approach for Building Trades Councils to Plan and Implement Multi-trade, Market-wide, Workforce Organizing Campaigns" - to encourage councils to provide more decisive leadership in organizing. The "Milestones to Organizing" document defines a series of thresholds that councils must cross to access BCTD assistance, staff and resources.

4. The COMET is enthusiastically endorsed and utilized by virtually every trade. Demand for the program is deep and widespread. One way to meet that demand, given the Department's limited resources and staff, is to assemble an extended team of educators beyond the building trades. To that end, the Department has surveyed university-based labor education centers to determine the availability of trainers for its various programs.

5. While the surveys indicate wide participation, they also reveal shallow penetration of COMET training. About $30 \%$ of the locals claimed to have trained a majority of their members, but almost $50 \%$ of the respondents reported reaching less than $20 \%$ of their rank and file. Therefore, the Department sees an ongoing need for COMET training to build deeper support for organizing among current union leaders and members.

6. Because very few business managers participated in the train-the-trainer courses evaluated by the Department, there was some concern that COMET instructors might be well prepared to deliver an organizing message to members but not well supported by the chief elected officer of their local union. The Department thus identified a need to win the political support of more business managers by either requiring their participation in Department-sponsored COMET Train-the-Trainer Courses or offering another forum for them.

7. The evaluation demonstrates that a relatively small minority of COMET trainers are delivering a significant majority of the training. Because the COMET I Train-the-Trainer Course is an instrument of organizational and cultural transformation, it is desirable - for political reasons - for leaders who may never actually deliver COMET classes to participate in the four-day course. But if sponsoring councils (and international affiliates, for that matter) enforced a more selective criteria for enrollment in train-the-trainer courses, they might be able to maximize the output of skilled trainers who actually deliver COMET classes to rank and file members.

8. While survey respondents generally claimed to have encountered few problems in delivering the COMET class, the most common difficulty that they did identify was class attendance. Results also indicate that many trainers conduct relatively small classes, which is an inefficient use of union resources. Some respondents have addressed this problem by requiring apprentices to attend COMET classes. Unions and councils that decide to utilize the COMET 
should be prepared for the labor intensive internal organizing that is necessary to recruit adequately sized classes. Moreover, the Department is considering the development of new COMET "products" that can be delivered to members in shorter time frames (perhaps 45 minutes rather than the full 3-4 hours) and in non-classroom settings (like jobsites or regular union meetings).

9. Most respondents expressed confidence in their own ability to conduct COMET classes. The Department did not attempt to independently judge the quality of training being delivered. But the Department recognizes that reaching large numbers of members is important only if they experience excellent training. There has been no systematic method devised to provide ongoing "quality control" for COMET training; one is urgently needed.

10. The Department's efforts to evaluate its COMET programs were hindered by the lack of a uniform reporting and tracking system and the absence of baseline, pre-training surveys. The evaluation process itself motivated the Department to develop and implement these instruments.

11. Successful organizing in the building trades requires a critical self-examination of internal policies and procedures that, in fact, impede the recruitment of new members. While the survey respondents claimed that such a self-examination had occurred in those locals that used the COMET, the Department remains somewhat skeptical that the process of internal change has progressed far enough to sustain widespread organizing. The Department hopes to encourage a real "change to organize" process by conditioning its support and assistance to councils on the willingness of local affiliates to dismantle internal obstacles to organizing.

12. Finally, while survey respondents reported widespread organizing activities stimulated by COMET, every indication suggests that even those affiliates earnestly recruiting new members and pursuing nonunion contractors have not yet succeeded in organizing large numbers of workers. The Department is advocating a workforce organizing approach that involves massive worker outreach, identification of issues, cultivation of leaders from the unrepresented workforce, building functional and representative committees and concerted action to unionize open shop contractors. The COMET evaluation reinforced the Department's view that much progress has been made, but that much more is still needed to truly re-unionize the construction industry.

\section{Conclusion}

The construction industry was once among the most densely unionized sectors of the American economy. In the post-war period unionization has declined from about $80 \%$ to $30 \%$ of the industry. The building trades have responded with a renewed commitment to organizing, driven to some extent by the COMET program. It is rare that a labor education program plays such a pivotal role in union revitalization. COMET delivery in a multi-trade context has encouraged a cross-fertilization of ideas among different affiliates and created the opportunity for coordinated organizing by building trades unions.

As it struggles to engineer the re-unionization of the construction industry, the Building and Construction Trades Department faces a paradox. While the resources, power and capacity to act rest primarily with its affiliates, many leaders recognize that the future of building trades 
unionism depends upon the ability of the Department, at the national level, and councils, at the local level, to coordinate and drive multi-trade organizing. That demands that these central, "federated" bodies play a much more determined and directive role than they are generally accustomed to playing. The seriousness with which the Department has approached its role in leading a construction organizing movement is impressive. The delivery - and systematic evaluation - of its multi-trade COMET training represent only one element of the Department's effort to promote union organizing. Its "Milestones to Organizing" initiative and the recent creation of a position to assist President Georgine in shaping all Department activity around a clear organizing agenda are further evidence of its commitment to re-unionize the industry. Perhaps the lessons the Department learns will be instructive for the AFL-CIO as it attempts to spark a resurgence in the entire labor movement.

\section{Bibliography}

Employment and Earnings. "Table 42 of Household Data Annual Averages," Bureau of Labor Statistics, Washington, D.C. January, 1996 and January, 1998.

Grabelsky, Jeff, "Lighting the Spark: COMET Program Mobilizes the Ranks for Construction Organizing," Labor Studies Journal. Spring, 1995. 